\title{
Enfoque Comunicativo y Cultural de la Situación de los Profesionales de la Salud frente a la Pandemia de COVID-19
}

\section{Communication and Cultural Approach to the Situation of Health Professionals in the Face of the COVID-19 Pandemic}

Cristina Lázaro-Pérez. Universidad de Murcia. España.

cristina.lazaro2@um.es

[CV] 1 (1) $\mathrm{R}^{\circ}$

José Ángel Martínez-López. Universidad de Murcia. España.

jaml@um.es

$[\mathrm{CV}]$ (1) $\mathrm{R}^{\circ}$

José Gómez Galán. Universidad de Extremadura. España / Universidad Ana G. Méndez. Puerto Rico

jgomez@unex.es / jogomez@uagm.edu

$[\mathrm{CV}] \bigcirc \mathrm{R}^{\circ}$

María José del Pino Espejo. Universidad Pablo de Olavide. España.

mjpinesp@upo.es

$[\mathrm{CV}] \bigcirc \mathrm{R}^{\circ}$

Lázaro-Pérez, C., Martínez-López, J. A., Gómez-Galán, J. y Del Pino Espejo, M. J. (2021). Enfoque Comunicativo y Cultural de la Situación de los Profesionales de la Salud frente a la Pandemia de COVID-19. Revista Latina de Comunicación Social, 79, 357380. https://www.doi.org/10.4185/RLCS-2021-1530

\section{RESUMEN}

Introducción: El inicio de la tercera década del siglo XXI será recordado por la pandemia de COVID-19 y la crisis sanitaria que ha producido, modificando sistemas como el cultural, el político, el económico, el mediático o el comunicativo. Desde la antropología de la salud, se pueden observar las interconexiones entre el sistema sanitario, la comunicación y la cultura, todas ellas indivisibles por los muchos enfoques que conviven y que configuran un campo de análisis propio. Metodología: Esta investigación empírica se ha desarrollado desde una vertiente cualitativa a través de 40 entrevistas semiestructuradas en España durante el momento álgido de la crisis sanitaria en el Estado de Alarma- e investiga cómo afectó esta pandemia a los profesionales sanitarios durante la primera oleada de la misma. Ellos fueron la barrera fundamental para hacer frente al coronavirus SARS-CoV2, y realizaron su trabajo en condiciones extremadamente precarias, sin apenas equipos de protección individual, ni recursos humanos suficientes, ni las infraestructuras imprescindibles para atender a los pacientes. Resultados/Discusión: El estudio se centra en tres dimensiones: (a) los aspectos culturales 
que impregnan la actividad profesional de los sanitarios, (b) los aspectos emocionales en el desarrollo de la misma sobre los procesos de duelo y muerte desde sus componentes simbólicos, y (c) las percepciones que tiene de la gestión sanitaria realizada por la respuesta pública. Conclusiones: Los resultados describen la situación extrema a la que tuvieron que enfrentarse estos profesionales, en una crisis sanitaria sin precedentes en décadas, que refleja un nuevo escenario antropológico y sociológico.

PALABRAS CLAVE: COVID-19; comunicación, cultura, pandemia, antropología de la salud, sociología de la salud

\begin{abstract}
Introduction. The beginning of the third decade of the 21 st century will be remembered for the COVID-19 pandemic and the health crisis it has produced, altering different systems such as the cultural, political, economic, media and communication systems. From the anthropology of health, the interconnections between the health system, communication, and culture can be observed, visible and indivisible by the many edges that coexist and conform to a field of own analysis. Methodology: This empirical research has been developed from a qualitative perspective through 40 anonymous semi-structured interviews in Spain during the height of the health crisis - in the state of alarm - and investigates how this pandemic affected health professionals during the first wave of the pandemic. They were the fundamental barrier to deal with the SARS-CoV-2 coronavirus, and they carried out their work in highly precarious conditions, with hardly any personal protection equipment, sufficient human resources, and the essential infrastructures to care for patients. Results/Discussion: The study focuses on three dimensions: (a) the cultural aspects that impregnate the professional activity of the health workers, (b) the emotional aspects in the development of the same about the processes of mourning and death from its symbolic components, and (c) the perceptions it has of the health management carried out by the public response. Conclusions: The results describe the extreme situation these professionals in a health crisis without precedent in decades, reflecting a new anthropological and sociological scenario.
\end{abstract}

KEYWORDS: COVID-19; communication; culture; pandemic; health anthropology; health sociology

\title{
Contenido
}

1. Introducción. 2. Marco Teórico. 3. Metodología. 4. Resultados. 5. Discusión y conclusiones. 6. Referencias. 7. Currículum Vitae

Traducción realizada por Paula González (Universidad Católica Andrés Bello, Venezuela)

\section{Introducción}

La antropología, como ciencia social, se ha basado en la ciencia empírica para comprender como los seres humanos se relacionan y experimentan la realidad vital de sí mismos y de los demás. Entender los escenarios y circunstancias del resto de sus semejantes ha sido fundamental para establecer relaciones sociales estables y significativas.

Una manera de establecer vínculos con la sociedad es mediante el surgimiento del sufrimiento social, que, como señala Anton (2017), no es causado solamente por el malestar físico y su impacto emocional, sino que se refiere a una expresión de la condición humana más extraordinaria, que es la base de la Evolución Cultural. Una cultura que actualmente, está definida por los procesos 
comunicativos y mediáticos (Gómez-Galán, 2015 y 2020; Hartley et al., 2020; Sheldon et al., 2020; Kristensen, 2021; Barrientos-Báez, 2019b)).

Por tanto, el sufrimiento social ocurre cuando hay una confrontación entre las creencias y valores de la sociedad y los de los individuos o la imposibilidad de aplicarlos (Sarmiento Guede y Rodríguez Terceño, 2018). Aquí, es la tensión de la adaptación social que induce la aparición de enfermedades, tanto físicas (enfermedades ocupacionales) y psicológicas (depresión, estrés, ansiedad, etc.) tan frecuentes en sociedades complejas y que responden a la falta de sentido.

Sin embargo, a través del desarrollo de la empatía social, la antropología médica se abre paso dado que reconcilia los campos de la antropología socio-cultural y biológica o física, entre otros, con la medicina y la salud pública (Kiefer, 2006; Baer et al., 2016). Estudia las dimensiones biológicas, psicológicas, culturales y sociales, que determinan como las personas entienden y viven la salud y sus problemas de salud. Su objeto de estudio y análisis son los diferentes sistemas, creencias y prácticas referentes a la salud y el proceso salud-enfermedad en cualquier sociedad (Díaz et al., 2015).

A lo largo de la historia, los conceptos de salud y enfermedad han cambiado dependiendo de la cultura, sociedad, y la forma en que se establecen; es, por tanto, su manera de entender la salud, la enfermedad, y la relación entre ambas, que se ha denominado salud-enfermedad-cuidado (cura) (Ramírez-Velázquez, 2018). El sufrimiento (o la angustia) también tendría un rol fundamental y se articulan en la biología, ecología, y cultura (Gómez Cardona, 2013) como un sistema que debe ser analizado como un todo considerando la proyección bio-cultural de una sociedad en particular. Esto debe de ser tomado en cuenta desde una perspectiva metodológica cuando se relaciona con la comunicación (Aneas y Sandín, 2009; Aladro Vico, 2020; Martín-Antoranz et al., 2019; SanjuanPérez et al., 2020). Como Díaz et al. (2015) sostienen, reconocer los elementos sociales en el proceso de la salud-enfermedad-cuidado, nos ha permitido entenderlo como un proceso histórico, social y culturalmente determinado. Dado que la cultura es una prerrogativa humana, está entronizada en cualquier análisis, para, sobre todo, generar teorías, métodos, y prácticas culturalmente competentes. En este aspecto radica la importancia de considerar la salud como un espacio antropológico.

La salud y las estructuras creadas para promoverla son parte de un sistema social y cultural propio. El enfoque médico de la salud, desde una perspectiva biológica, es actualmente demasiado limitado para entenderlo en su complejidad. La biomedicina por sí sola no puede cubrir todas las necesidades de salud de la población. La salud es parte de la experiencia de vida de las personas, y la vida no está restringida a sus aspectos fisiológicos; por tanto, la salud no puede reducirse al enfoque biomédico. (Junge, 2001).

Teniendo en cuenta esta visión, es necesario entender, desde un punto de vista biocultural, las reacciones de los protagonistas a estas percepciones que subyacen a la pérdida de salud y no solo como un objeto sin emoción. Dado que el ser humano es un ser multidimensional y la salud contempla no solo lo biológico sino también lo cultural, como un estado que legitima la emoción y el sufrimiento, la salud puede ser concebida desde dos puntos de vista: Desde del que sufre lo físico y desde aquel que contempla el sufrimiento de otros.

La dimensión de la salud desde una perspectiva individual y comunitaria sitúa un escenario antropológico en el que la pérdida de la salud marca el actual "fenotipo cultural" (Carja y Creanza, 2019) de una sociedad que se consideraba enferma, cuya cura se encuentra precisamente dentro de la misma sociedad. No es extraño entonces entender la salud humana como un proceso biocultural que 
interactúa con otras disciplinas como la biodemografía y la epidemiología (Díaz et al., 2015) en el marco de la antropología médica.

Por tanto, las costumbres, tradiciones, significados, símbolos, concepciones, percepciones y representaciones sobre la salud y su pérdida que tenemos como un grupo social y como individuos, es fundamental para manifestar y comprender la forma, no solo de actuar contra ellos, sino también para elaborar patrones representativos de la sociedad a la que pertenecemos. Asimismo, si movemos nuestra mirada más allá del propio objeto de la cura, podemos adentrarnos en las interacciones y componentes simbólicos del sistema de salud, e introducirnos en las relaciones y características del personal de salud, imprescindible para el funcionamiento del sistema de salud.

\section{Marco teórico}

El escenario de estudio es una nueva epidemia en un contexto cultural distinto. A través de la historia, distintas sociedades han enfrentado muchas epidemias (Gómez-Galán, 2020; Roman et al., 2020; Guerra Rubio y Eiriz García, 2018). Sin embargo, nuestra especie ha sobrevivido y convivido con enfermedades infecciosas que han cobrado la vida de millones de personas (Mestre Ortega, 2018). Cabe recordar, por ejemplo, la viruela, el sarampión, la gripe española del siglo $X X$-aunque su nombre encubría su verdadero origen y extensión- y recientemente el VIH, virus ligado a importantes connotaciones sexuales y comportamientos sociales de rechazo y prejuicio, pero también vinculado al sufrimiento, la enfermedad crónica o la muerte (Sevilla y Álvarez, 2002).

La capacidad del ser humano para superarse a sí mismo está registrada a través del tiempo, como reflejó Charles Darwin en 1859 con la publicación de El Origen de las Especies. Si bien los seres humanos se han relacionado con el riesgo y la proximidad de la muerte, la inseguridad, la inestabilidad, el miedo y la falta de sentido son los sentimientos más frecuentes en sociedades complejas (Antón, 2013).

Debido a los procesos de globalización y de implementación del estado del bienestar en los países más desarrollados, generaciones de ciudadanos han nacido y crecido con una sensación de seguridad inimaginable para sus antepasados, aunque no está exenta de los nuevos riesgos de nuestra era. Como sostiene Vázquez (2008), la civilización altamente tecnológica, el estado del bienestar, el mercado mundial, la esfera mediática: todos estos grandes proyectos quieren imitar la vieja seguridad de las esferas en una época que se ha hecho añicos, pero esto se ha vuelto imposible.

La pandemia de COVID-19 ha causado, en poco tiempo, cambios estructurales en las dimensiones sociales, culturales y sanitarias de gran parte del mundo (Barneveld et al., 2020; Buheji et al., 2020; Douglas et al., 2020; Vega Jiménez, 2021; Hernández-Fernández, 2021). El número de infecciones y muertes está en un escalofriante aumento diario desde los primeros meses de 2020, transformando la forma en que socializamos -acentuando las infraestructuras virtuales- las relaciones interpersonales, las rutinas diarias, la dedicación personal y el procedimiento político (Rodríguez Vidales, 2010).

Aunque existían algunos protocolos a aplicar según dos grandes organismos internacionales como la Organización Mundial de la Salud (OMS) y, en España, el Centro de Coordinación de Alertas y Emergencias Sanitarias debido a crisis anteriores, la velocidad de transmisión del virus y su alta letalidad, han hecho que el distanciamiento social aplicado haya sido aceptado de forma voluntaria e incluso autoimpuesto en la mayoría de los casos. Los fenómenos sociales básicos han determinado las formas alternativas de proceder en la comunicación del ser humano como agente social y cultural circunstancial (Tomasello, 2010: Merril et al., 2020; Hsieh y Kramer, 2021; Romeu, 2016). 
En esta nueva realidad radical, la vida, como máxima representante de todos los estratos que identifican y definen al ser humano y el medio ambiente, intenta abrirse camino siguiendo un modelo natural con tres perspectivas: ecológica, simbólica y política (Santamarina, 2008). La estrecha relación entre la naturaleza y el ser humano obliga a la observación de la persistencia y la necesidad de supervivencia de la primera a pesar de la segunda, superando con imponente hegemonía al hombre en el momento en que se retira para proteger a su especie, esta relación continúa vigente siempre y cuando no se pueda ignorar la influencia que el medio ambiente puede tener sobre el cuerpo y la cultura. La privación de estímulos sensoriales como el calor del sol y el aire puede alterar el comportamiento biológico y psicológico del ser humano, y aunque existe una adaptación al ambiente cerrado, el confinamiento sigue siendo un mero procedimiento sanitario.

En su sentido simbólico, el ser humano necesita desarrollar de manera significativa el efecto que la privación de la red social tiene en los vínculos con otras personas. Los instrumentos y formas de comunicación actuales han establecido un modelo alternativo de socialización (Bacallao-Pino Lázaro, 2016); un factor significativo que cabe destacar es la confianza depositada en las nuevas tecnologías y la ciencia. Sobre las primeras, estas han creado distintos medios de incursión en la realidad humana y plantean nuevos paradigmas y representaciones culturales para dotar de significado a los escenarios actuales y crear estilos de vida inesperados y ajustados a la nueva realidad. Nos referimos al uso frecuente de las nuevas tecnologías como medio de comunicación, es decir, el uso de Internet a través de videollamadas o mensajes como nuevo método de socialización debido a las privaciones a las que estaba sometida la población como consecuencia del encierro. En esta misma línea de argumentación, Escobar (2005) defiende que los constructivistas han demostrado que la contingencia y la flexibilidad son las esencias del cambio tecnológico, contrario al determinismo tecnológico del pasado. Al demostrar que los procesos sociales son inherentes a las innovaciones tecnológicas, han asestado un golpe decisivo a la supuesta distancia entre tecnología y sociedad y entre tecnología y naturaleza.

Hay que tener en cuenta que la globalización, los medios de comunicación, la agenda pública, tanto los gobiernos como los organismos supranacionales, hacen que la pandemia actual sea vista como una serie de hechos desgarradores y apocalípticos que suceden al mismo tiempo, y esta sensación de seguridad colectiva alrededor de la salud que hasta ahora había permeado el imaginario colectivo en los países más desarrollados, desaparece. Esta nueva crisis de salud resalta el dolor desde una perspectiva maximalista. El dolor impregna las emociones, y la velocidad de los acontecimientos impide, en la mayoría de los casos, adaptarnos con la rapidez necesaria (Ruiz Torres, 2021; Castañeda-Hernández y Rodríguez López, 2020).

En este momento, el dolor es visible en España desde diferentes perspectivas, pero principalmente perceptible en los hospitales y su personal sanitario, ya que han sido el epicentro donde se ha llevado a cabo la lucha contra este virus, como pocos recuerdan en otras epidemias similares. Los profesionales de la salud son conscientes de lo que significa el dolor, trabajan con él, también con la curación (Fernández et al., 2020). Como sostiene Molina (2011), los profesionales de la salud tenemos la obligación moral de ampliar nuestra visión del paciente, descubrir el sufrimiento y localizar en la medida de lo posible su origen, y utilizar todos los medios a nuestro alcance para aliviarlo, teniendo en cuenta al hombre en su dimensión holística.

A través de las imágenes transmitidas por los medios de comunicación, se han percibido las reacciones emocionales de los profesionales de la salud en estos momentos de tanta tensión producidos por la crisis de salud, desde la tristeza y la impotencia por la falta de equipos de protección personal, en adelante EPP, y falta de equipos de salud, al orgullo y reconocimiento por los aplausos en los balcones (Lominchar Jiménez, 2020). Además, estudios recientes abordan la 
situación actual de los proveedores de atención médica. Bellizzi et al. (2020) destacan que el agotamiento físico y mental, el dolor de perder pacientes y colegas, el miedo a transmitir la infección a sus familiares y el tormento de decisiones de triaje difíciles complementan una situación complicada. Por tanto, es fundamental señalar la importancia de la inteligencia emocional para evitar estas situaciones (Barrientos-Báez, 2019a).

En este sentido, una forma emergente de adaptarse a las peores circunstancias de esta situación generada por el COVID-19 han sido las novedosas formas de despedida del fallecido. Si bien la antropología ha destacado, desde sus inicios, como los ritos más inherentes al ser humano, analizados desde las distintas vertientes y campos gnoseológicos, ahora las Tecnologías de la Información y la Comunicación han propuesto una nueva forma de despedida. Reúne a quienes no pueden acompañar a sus seres queridos en hospitales y cementerios por el distanciamiento social que dicta el gobierno nacional. A través de ellas y las plataformas accesibles, las despedidas se han podido realizar, de manera virtual, tanto en centros de salud como en cementerios, a través de videollamadas, donde los familiares han tenido la oportunidad, a lo lejos, de ver y despedirse de sus seres queridos. Los nuevos rituales han sido avalados por las redes sociales que se han convertido en el tablón de anuncios de los obituarios, siendo un espacio donde decir el último adiós, manifestar las emociones de dolor y tristeza, y expresar el duelo por el fallecido. Si bien el estado de encierro proporciona nuevos recursos para la adaptación, el ser humano, como ser social, necesita el contacto y la presencia como elemento crítico para elaborar procesos de angustia y duelo, para ayudar a los enfoques virtuales. Sin embargo, no consolarán a los dolientes, que inmortalizarán esta forma inconclusa de despedida. Además de convivir a diario con la muerte, los profesionales sanitarios también han vivido esta forma de despedida, ya que, como parte activa de la sociedad, muchos de ellos han sufrido la pérdida de familiares y compañeros a los que no han acompañado.

La tercera perspectiva del modelo es la política, que ha surgido en la etapa de encierro, principalmente con las formas alternativas de proceder y los decretos establecidos en el estado de alarma. La pluralidad de opiniones sobre la política proporciona un nuevo marco para observar las reacciones de las personas, especialmente en un estado de aislamiento social. Las anteriores normas de selección natural de amistades han sido modificadas por las diferentes visiones de ver y comprender la sociedad y la condición, y la expresión de los sentimientos propios y ajenos, amplificados por la privación social, principalmente a través de las redes sociales. La política genera tensiones sociales haciendo los actos realizados o expresados como sociedad y como seres sociales comprensibles, pero no siempre justificables. Estas tres perspectivas del modelo natural (ecológico, simbólico y político), que han sido reveladas durante la crisis de salud que se generó tras la aparición del COVID-19, y las consecuencias derivadas de ellas (García-Martín et al., 2021), pueden provocar un estado de estrés y ansiedad importantes que, de no esperarse, podrían derivar en un estilo de ansiedad permanente. Es crucial el caso de los profesionales de la salud que viven, como se mencionó anteriormente, situaciones vitales agudas por el contacto constante con la enfermedad y la muerte (Lázaro-Pérez et al., 2017; Herrero y Toledo Chávarri, 2012). Se puede afirmar que la enfermedad y el cuidado configuran hechos estructurales en toda sociedad y que el cuidado de la enfermedad expresa las características de la sociedad en la que se desarrolla y opera (Evia, 2015). Como señala Mas Esquerdo (2020), los estudios sobre la psiquiatría de las pandemias apuntan a un aumento de los trastornos de ansiedad y depresión, así como a secuelas postraumáticas y a la cronificación de la psicopatología postpandemia como consecuencia de la inusual exposición a la fatiga por compasión, la angustia moral y el estrés al que fueron sometidos estos profesionales durante los meses más desafiantes de la pandemia.

En este sentido, Vargas y Casillas (2007) defienden que la cultura (espacio en el que los individuos expresan su comportamiento tanto individual como colectivamente, influenciados por las emociones 
RLCS, Revista Latina de Comunicación Social, 79, 357-380

[Investigación] DOI: 10.4185/RLCS-2021-1530| ISSN 1138-5820| Año 2021

y sentimientos inherentes a sus componentes) es la que marca el comportamiento y costumbres de la sociedad en torno a la enfermedad y la muerte, incluyendo ideologías y creencias.

\section{Métodos}

Lo que orienta la investigación antropológica es conocer cómo la actual crisis del COVID-19 puede afectar a los profesionales de la salud encargados de librar esta batalla en los centros de salud (Cerezo Prieto, 2020). Estudios recientes muestran las consecuencias presentes en estos trabajadores y hacen una prospectiva de cómo será el regreso de la supuesta normalidad, y cuáles pueden ser los efectos postraumáticos para estos profesionales (Vargas Delgado, 2020). En este sentido, Guanche (2020) señala, sobre la exposición de los profesionales de la salud, que el mayor desafío actual es la formación de los trabajadores de la salud en estos temas y el logro de la prevención de la transmisión de infecciones en los centros de salud. Por otro lado, no se pueden ignorar los aportes de Semple y Cherrie (2020) sobre la necesidad de establecer medidas de control y planes de prevención para prevenir la propagación de enfermedades entre la población; elementos clave no solo para el personal de salud sino también para los responsables de la gestión pública.

Esta investigación se basa en el supuesto de que existen múltiples interconexiones entre los sistemas de salud y culturales en la protección de la salud. Como afirmaron Langdon y Braune (2010), el sistema social de salud se define como aquel que está compuesto por instituciones relacionadas con la salud, la organización de los roles de los profesionales de la salud que participan en él, sus reglas de interacción y las relaciones de poder inherentes al mismo.

En este sentido, se desarrolla una mirada empírica reivindicando la antropología de la salud, marco sobre el que está estructurado este trabajo (Díaz et al., 2015), teniendo en cuenta la perspectiva de la antropología médica interpretativa y la antropología crítica, siendo objeto de estudio el personal sanitario que se ha encargado de dar respuesta a la actual pandemia del COVID-19 en España. De esta manera, damos voz a los protagonistas de la crisis de salud, escuchando sus discursos, enfoques, percepciones, etc., a través de una metodología cualitativa con entrevistas semiestructuradas sustentadas por la presentación de fotografías sobre temas cruciales en este momento histórico, para comprender, desde un enfoque individual y colectivo, el proceso y la combinación salud-enfermedad generadas por la aparición del coronavirus. Finalmente, tomando como referencia estas cuestiones interpretativas y fenomenológicas, los discursos de los participantes se abren paso en el análisis de la enfermedad, la muerte y la gestión pública a través de sus narrativas.

En cuanto al período de tiempo, el trabajo de campo se realizó en el momento en que la sociedad española se encontraba en total confinamiento entre el 6 y el 19 de abril de 2020, cuando se alcanzó el pico de casos activos de COVID-19 en España. En términos de ámbito geográfico, la investigación se desarrolló en las siguientes Comunidades Autónomas: Madrid, Cataluña, Valencia, Navarra, Andalucía, Castilla-La Mancha, Castilla y León, Murcia, Islas Baleares e Islas Canarias. Se realizaron cuarenta entrevistas anónimas semiestructuradas con diferentes perfiles de salud que laboran en diferentes servicios hospitalarios. No hubo selección previa de participantes en cuanto a perfil, y la invitación a participar en la investigación se realizó a través de los representantes de los trabajadores de los centros hospitalarios y grupos de difusión de información. Ante la imposibilidad de realizar las entrevistas personalmente a raíz de la aprobación del Real Decreto 463/2020, del 14 de marzo, por el que se declara el estado de alarma -y que posteriormente se prorroga- las entrevistas se llevaron a cabo mediante videoconferencia. Los temas utilizados en las entrevistas fueron: 1) cambios en los hábitos de la vida diaria, 2) cómo concilian su vida cotidiana con el trabajo y el riesgo de COVID-19, 3) preocupaciones actuales, 4) cómo evalúan la gestión realizada por las diferentes 
administraciones públicas, 5) actitudes, emociones y sentimientos de los actores sociales durante el encierro, 6) influencia del COVID-19 en la dinámica laboral, 7) cómo han sentido/percibido la imposibilidad de los familiares de los pacientes afectados por el COVID-19 de acompañarlos, 8) mortalidad de pacientes en soledad.

Todos los participantes dieron su consentimiento informado en virtud de la Declaración de Helsinki. Asimismo, y aunque no fue necesaria la aprobación oficial de las universidades españolas a las que pertenecían los miembros del equipo de investigación -dado que es un estudio descriptivo y solo se requiere en los trabajos experimentales, firmaron los Códigos de Buenas Prácticas para la Investigación en Seres Humanos, como los recogen los Comités de Ética. El estudio fue registrado (código No. REPRIN-PEM-02) por el equipo de investigación de los autores.

Se eligió la técnica de entrevista semiestructurada porque es relevante cuando el contexto, el estudio o cualquier otra circunstancia hacen que sea la única oportunidad para entrevistar a los participantes. Además, es especialmente aconsejable cuando se hace a técnicos, que son especialistas en un tema en particular, pero dejan libre a la persona que las guía para redirigir la entrevista a través de pistas o direcciones (Russell, 1995). Lo visual complementó esta técnica de entrevista semiestructurada ya que se incluyeron una serie de imágenes para que las describieran los profesionales de la salud. El uso de imágenes en estudios antropológicos ha aumentado cada vez más, pero no es una técnica nueva, ya que incluso Malinowski (1967), Mead y Bateson (1977) o Lévi-Strauss (1994) han dejado la huella de la fotografía en la antropología.

Existe evidencia científica de que, en los meses y años posteriores a un desastre, hay un aumento en los trastornos de estrés depresivo, ansiedad y postraumáticos (Van Ommeren y Saxena, 2005; Huremović, 2019). Por ello es necesario conocer aquellos factores que podrían estar implicados en la aparición y desarrollo de estos trastornos, atendiendo a los aspectos y factores que atentan contra la salud mental y que se recogen en las preguntas planteadas a los participantes, como los que generan estrés postraumático, fatiga por compasión y angustia moral (Mas Esquedo, 2020).

Conscientes de los beneficios de la fotografía en la investigación antropológica, las utilizamos para que los entrevistados puedan mostrar sus percepciones, conexiones e interrelaciones entre las diferentes variables de un mismo fenómeno, en este caso, las acciones de los profesionales de la salud en la actual crisis de salud. En definitiva, a través de las fotografías, queremos saber cómo identifican y construyen su microcosmos laboral desde una perspectiva crítica.

\section{Resultados / Discusión}

La actual crisis de salud ha cambiado nuestro estilo de vida y nuestras percepciones sobre los hábitos, el presente y, por supuesto, el futuro. La seguridad de la vida y las rutinas diarias ha sido interceptada por un halo de desconfianza que afecta a la sociedad. La población ha sufrido estos cambios, pero se han incrementado en los profesionales de la salud ya que han permanecido en sus puestos de trabajo; han tenido que conciliar sus obligaciones familiares mientras continúan con algunas rutinas básicas como ir a supermercados o farmacias. Esto ha supuesto una carga adicional para el contexto laboral y ha condicionado su situación de cierta manera.

\subsection{Entrevista semiestructurada: preguntas abiertas}

Estas circunstancias han provocado que su actividad profesional haya influido significativamente en los hábitos de vida del personal sanitario, por el caos vivido en los primeros días, la falta de respuesta de las instituciones sanitarias y la incapacidad para detener la eclosión del virus. Por tanto, la fatiga, 
el nerviosismo, la preocupación, la inquietud, el miedo y la ansiedad han sido constantes en la forma en que los profesionales de la salud se han tenido que adaptar a esta situación:

"Los primeros días sí, porque en el trabajo se respiraba un ambiente con mucha tensión, nervios, sin saber actuar, comportarse, cambios constantes, un día una cosa y al día siguiente otra. Sin embargo, a medida que pasan los días, la situación se vuelve cada vez más controlada y más fácil de tratar".

¿¿Las primeras veces sentí que iba a la guerra? Luego me acostumbré".

"Sin duda alguna, ninguno de nosotros estaba preparado para esta situación, y la incertidumbre era un sentimiento con el que el personal de salud tenía que lidiar durante las primeras semanas".

"Inicialmente, estaba ansioso por la situación".

"Desconocimiento. Falta de EPP, falta de previsión, cambios continuos de protocolos".

"Profesionalmente, el colapso de los servicios de emergencia y la posibilidad de escasez de camas en la UCI. Personalmente, el miedo de contagiar a mis padres y/o familiares y hacer que se enfermen o incluso mueran por mi culpa".

"La sensación de irrealidad y miedo ante la incertidumbre".

"Intento tener una actitud positiva, pero no puedo tener una vida normal ni salir a la naturaleza. Tristeza, impotencia, malestar, ansiedad...".

"Negación, ira, miedo, impotencia, aceptación".

"Una montaña rusa de emociones. Un día estoy feliz y activo, y al día siguiente estoy triste y no quiero levantarme de la cama".

Las relaciones familiares también se han visto afectadas por muchos profesionales de la salud ya que esta situación hizo necesario realizar una triple protección: cuidar de los pacientes, de ellos mismos y de sus familiares. Las administraciones públicas han puesto al servicio los hoteles sanitarios para evitar poner en peligro de contagio a sus familias. Aunque, entre los informantes, pocos lo han elegido, pues ha sido muy traumática para quienes la han elegido. Como resultado, la mayoría optó por el autoaislamiento en casa, no interactuando con sus familias, encerrándose en una habitación durante el encierro y saliendo solo para ir al hospital a trabajar, para evitar el riesgo de contagio:

"Estaba aterrorizado por mis hijas, mi esposa y yo que no tenemos EPP y tuve que salir de casa, lavar mi ropa en un lavadero..., compré mi EPP, mi vida, la vida de mi familia y mi salud están por encima de todo. Psicológicamente, terrible para mi familia y para mí, estuve 20 días solo y en un sótano que solo tenía piso, una bombilla, sin ventanas, estaba helado, sin medidas de higiene, porque solo tenía un lavabo y un baño, nevera y microondas. El famoso hotel sin acceso y sumamos sin el apoyo de nuestra gerencia. Podría seguir, pero bueno, la presión ha sido brutal en el trabajo y en mi día a día solo y esas condiciones".

"En este momento estoy bien, aislado en el dormitorio sin ver a la familia que vive en casa, una esposa y dos hijas, la razón: al estar al cuidado de pacientes con COVID-19, no puedo darme el lujo de contagiarlos si lo contraigo, por seguridad, solo salgo a trabajar cuando es mi turno, básicamente esa es mi vida, acompañado de la radio y el celular. Así que no me quejo, es lo que toca". 
A estas situaciones de incertidumbre e incluso de pánico de los primeros días se sumó una dificultad más: la necesidad de conciliar la vida laboral y familiar. Los profesionales de la salud destacan la gran dificultad de compaginar trabajo y cuidados o, en otras palabras, situaciones laborales extremas (precaución contra el contagio, mantenimiento de constantes medidas de higiene, lavado permanente de la ropa y evitar cualquier contacto) con el cuidado de sus hijos, como consecuencia del cierre de centros educativos y guarderías principalmente, $\mathrm{u}$ otros familiares dependientes:

"El problema de tener que buscar a alguien que se quede con mis hijos, tres hijos menores".

"Ir a mi lugar de trabajo no es un problema para mí, ya que me reconforta mi trabajo. Sin embargo, en casa, he cambiado mis hábitos desde que dejé mi hogar y me mudé a una casa de campo, para no contagiar a mis familiares de COVID-19. Incrementar la higiene de manos, vestuario, preparación de alimentos...".

"Poco apoyo a los baños con niños en edad escolar que no pueden quedarse solos".

"Es muy duro, lo peor es cuando sales de casa para ir a trabajar y cuando vuelves a casa, por miedo a contagiar a tu familia".

"Personalmente, el miedo a contagiar a mis padres y/o familia y que por mi culpa padezcan una enfermedad o incluso mueran".

La falta de medios, indicaciones y cambios constantes en las pautas para el personal de salud han sido elementos que han contribuido a este aumento de la preocupación. Sin embargo, los profesionales de la salud hacen una conexión entre estos elementos y otros de mayor alcance, vinculados a la economía (Lora Ochoa et al., 2020), la política, etc.:

"Actuación tardía del gobierno, falta de medios de actuación del gobierno, falta de medios de protección y diagnóstico, consecuencias económicas".

"Desinformación, falta de claridad y unidad, eternas ruedas de prensa para no decir nada, sentimiento de mala gestión, repetidas malas compras".

"Me causa miedo y ansiedad, los EPP que se entregan han llegado tarde y en pequeñas cantidades, y a veces no son tan efectivos como uno quisiera".

Como podemos ver, la gestión de crisis es uno de los elementos sobre los que pivota el conjunto de percepciones de las personas entrevistadas. La dirección ha expuesto la imagen de los informantes sobre líderes políticos y administrativos:

"El retraso de las medidas de contención, de previsión ya que teníamos a Italia como ejemplo y modelo a seguir y no se hizo".

"El retraso en la toma de medidas y la falta de infraestructura sanitaria y manufacturera".

"La falta de equipos de protección personal, la falta de gestión y organización, la falta de planificación y un verdadero comité de expertos para hacer frente a una emergencia nacional de esta magnitud". 
En este contexto, han surgido emociones en algunos de los típicos participantes de un estado de estrés continuo en el trabajo, angustia frente a la vida cotidiana, incertidumbre sobre el curso de los hechos, riesgos para la salud individual y colectiva, e indignación por la gestión pública. Por tanto, el correcto manejo de las emociones es fundamental para paliar estos síntomas (Barrientos-Báez et al., 2019).

Muchas emociones de tristeza, desamparo, emoción por el apoyo de la sociedad, decepción por parte de algunos compañeros, miedo a contagiar a tus hijos y pareja, afectados por ver tanto dolor en los familiares".

"Aversión, rechazo, indignación".

"Dolor, soledad, abandono, pesadilla, indignidad, pesar, imprevisibilidad, llanto e incertidumbre, mal desempeño y manejo...".

Otro dato relevante encontrado es cómo la crisis del COVID-19 afecta el trabajo diario de los profesionales de la salud, en cuanto a su desempeño (García Otero y Hernández Palma, 2020), con horas interminables, aumento de la carga de trabajo, relaciones con compañeros y/o pacientes, y la ausencia de EPP, que ha exigido un trabajo en equipo y coordinación excepcionales, a pesar de la existencia de un clima de tensión continua.

Mayor carga sobre todo psicológica, pero con los socios más unión entre nosotros”.

"Malas medidas de seguridad, más compañerismo y con los pacientes más responsabilidad por su parte y un mutuo aprecio hacia el paciente/proveedor de salud".

"Más carga de trabajo y agotamiento mental, físico y psicológico, mayor estrés".

"Cuidados más prolongados, carga emocional, cambio de actitudes hacia los mismos diagnósticos".

A pesar de esta unión entre los trabajadores, momentos de tensión han puesto a raya la coordinación y su capacidad para resolver situaciones que antes no habían sido tan conflictivas:

"COVID-19 ha sacado lo mejor y lo peor de las personas, tanto de los compañeros como de los pacientes".

"El EPP es incómodo, agobiante, inseguro, no estoy acostumbrado a trabajar en estas condiciones y mi día está lleno de mucha tensión por todas partes".

"Cada advertencia aumenta el miedo y la sensación de riesgo. Todo el equipo experimenta más estrés y tensión".

"La relación con los compañeros de la misma unidad ha sido en la mayoría de los casos excelente, con apoyo y solidaridad, y en otros casos poco solidaria, dañina y con mínima empatía por compañeros, pacientes y familiares".

Aunque los EPP son una de las demandas extraordinarias de los profesionales de la salud, la paradoja es que también son una de las cargas físicas más importantes que han tenido que soportar en su jornada laboral. El calor que desprenden, la tensión de usarlos (como evidencia de la situación de 
riesgo que enfrentan), el miedo a que se rompan, etc., aumentan la tensión y el estrés en el personal de salud:

"Sí, mucho más trabajo y carga emocional y la desventaja de tener que trabajar con EPP, la incomodidad y la presión de un virus desconocido".

"Más cantidad y complejidad de los pacientes, sin mencionar todo el tiempo que dedicamos solo a vestirnos y protegernos cada vez que tenemos que verlos. Además, con los EPP, las condiciones de trabajo son peores; pasamos un mal rato en esos trajes, trabajando con los pacientes".

"Ha habido una gran metamorfosis de todo el sistema de emergencias. Cada alerta significa un aumento del miedo y la sensación de riesgo. Todo el equipo lo vive con más estrés y tensión. En cuanto a los pacientes, el EPP genera despersonalización y deshumanización. Además, la comunicación verbal también es más incómoda. A muchos ancianos les entra el pánico, y llegan dos extraños a los que solo les ven los ojos y a veces apenas nos oyen o nos entienden porque llevamos máscaras".

Uno de los elementos más destacados de una cultura es el entender la vida y afrontar la transición a la muerte. A diferencia de otros países, con la actual crisis sanitaria, se ha podido ver como el entendimiento y el proceso de acompañamiento al final de la vida han tenido que cambiar. El riesgo de contagio y la soledad en los últimos momentos de la vida, han caracterizado este proceso. Esto ha significado un modelo de trabajo diferente para los profesionales de la salud:

"Con deshumanización, poniéndose una venda en los ojos".

"Con tristeza, impotencia e imposibilidad de consolar a los familiares". "Creo que es terrible que nadie te tome de la mano".

En este sentido, en ocasiones han sustituido a las propias familias, que estaban ausentes a la fuerza, y se han quedado con los pacientes hasta el último momento. Las historias detallan con dolor que se quedaron en la habitación y les dieron la mano hasta que terminaron muriendo. Esta muerte en soledad es un proceso deshumanizador, y los profesionales de la salud temían que pudiera tener consecuencias psicológicas para ellos y sus familias:

"Muchas veces tienes que estrecharles la mano porque están solos".

"Tristeza, frustración, falta de autonomía para decidir cómo morir y cómo ayudar al moribundo". "Ésta ya es una situación muy injusta para mí, ética y moralmente. Porque todos podemos morir acompañados de nuestros seres queridos".

"Con gran dolor, nadie merece morir solo de esta manera". "Lástima, a la larga, reproduciremos la enfermedad mental".

"Un paso atrás en el cuidado de los enfermos. Tendremos que encontrar alguna medida al respecto".

Sin embargo, también ha habido situaciones excepcionales, donde luego de ofrecer la posibilidad de acompañar al familiar en los últimos momentos, los familiares rechazaron esta oferta, y las personas afectadas por el COVID-19 murieron solas: 
"Con el médico acordamos informar al familiar y que el paciente podría estar acompañado durante sus últimas horas. Entró un familiar y se le dio un EPP. Lo triste es que nadie de la familia quiso ir a pesar de la invitación y la clara transmisión de que estaba a punto de morir".

"He tenido que vivir con eso y la necesidad de que los familiares abandonen a los pacientes. Es una situación dura que genera sentimientos de tristeza y frustración".

Como se vio anteriormente, los profesionales de la salud han jugado un papel importante en esta crisis sanitaria. Han aparecido constantemente en los medios, siendo inusualmente la imagen de lucha y esperanza. Incluso desde el mismo día del anuncio de la declaración del estado de alarma, aparecieron hacia ellos muestras de cariño, amor y reconocimiento:

“La población está agradecida por la labor de los profesionales de la salud".

"Todo el hospital y toda la gente de fuera se ha dirigido a nosotros con múltiples muestras de afecto y ayudando de cualquier manera que pueden”.

"He sentido un gran reconocimiento por parte de mi familia, compañeros, sociedad y red de amigos. La sociedad ha entendido que hemos ido a la guerra bacteriológica y que no siempre estaban todos los medios disponibles. Pero nunca dudamos que era nuestro deber".

Pese a ello, aunque el aplauso se ha sentido como un apoyo social, esta percepción no es homogénea entre el grupo de profesionales, principalmente por la ausencia de EPP:

"Los aplausos me emocionaron los primeros días, incluso derramando algunas lágrimas; sin embargo, por parte del gobierno, no me he sentido para nada valorado; no miro los colores, sino que no nos dan el EPP adecuado".

"En ningún momento he estado de acuerdo con los aplausos de las 8 de la noche. No somos héroes, solo unos trabajadores más, pero con un trabajo desconocido para la sociedad".

"En lugar de aplausos, deberíamos pedir más protección para los trabajadores de la salud".

Como se refleja en este estudio, el estrés y la ansiedad han surgido como catalizadores de la tremenda presión social de los profesionales de la salud. Muchos de ellos han tenido que recurrir a ansiolíticos para neutralizar sentimientos de angustia y otras emociones relacionadas con episodios de alta presión. Es paradójico que, a pesar de las condiciones culturales (salir a la calle, proximidad y convivencia de vecinos y amigos, empatía con los problemas ajenos, etc.) y las condiciones ambientales de nuestro país (temperaturas templadas, largos periodos de sol, etc.), existen altas tasas de consumo de productos farmacológicos relacionados con la ansiedad:

"He aumentado ligeramente el consumo de ansiolíticos". "Incremento de ansiolíticos para conciliar el sueño por la noche".

"Necesitaré ayuda psicológica para el manejo del estrés". "Especialmente en falta de ejercicio y tomando ansiolíticos". "Utilizando ansiolíticos por no poder dormir".

El aumento del consumo de medicamentos ha sido una pauta seguida por los profesionales de la salud, pero ha habido un comportamiento dual ante el mismo hecho. Por un lado, desde un enfoque comunitario y ecológico de la salud, donde se concibe como una situación más allá del proceso 
antagónico de la enfermedad, lejos del modelo tradicional basado en el binomio salud/enfermedad (Páez, 2011), los profesionales de la salud han aumentado las actitudes preventivas hacia su salud, incorporando hábitos de vida saludables como un mayor ejercicio físico y una mayor alimentación saludable:

"Me obligo a mantener un horario, hacer actividades y tomar descansos. Como bien y trato de cuidar mi lado biológico".

"Hago más ejercicio y trato que mi alimentación sea lo más saludable posible".

En el polo opuesto, como antiestrés, los profesionales de la salud han incrementado el consumo de productos poco saludables, especialmente el consumo de alcohol y los caracterizados por altos niveles de edulcorantes. En las narrativas, justifican este cambio en los hábitos de consumo, relacionándolos en un contexto vacacional, un período festivo donde el consumo inusual de este producto es un rasgo.

"Falta de ejercicio, consumo de más cerveza, comer más dulces". "Como solo, pero bebo más alcohol que nunca y más dulces”.

"Comida sana, casera, no siempre sana, alcohol, comidas tipo cerveza para desconectar y con sentimientos de entrega".

\subsection{Entrevista semiestructurada: Preguntas con imágenes}

Como se describe en la metodología, la fotografía es un medio para adentrarse en diversos aspectos subjetivos de los profesionales de la salud para incrementar la intensidad y diversidad de sus discursos, complementando así la información brindada a través de las entrevistas.

La primera de estas muestra una imagen que sí quedará en la memoria, no solo en España sino también en otros países que también la adoptaron: balcones llenos de gente aplaudiendo a los profesionales de la salud a las 20:00 horas (Figura 1).

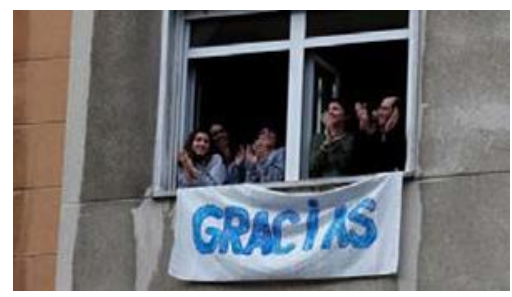

Figura 1: Balcones llenos de gente aplaudiendo a los profesionales de la salud a las 20:00 horas.

Fuente: Telemadrid. https://cutt.ly/AheM2AY

Los profesionales de la salud vuelven a expresar su gratitud. Los profesionales sienten emoción, gratitud, solidaridad y empatía. Sin embargo, el componente simbólico de estos actos de reconocimiento no se ha percibido de la misma forma a medida que han aumentado las semanas de encierro.

"España, fiestas de pueblo, charanga, bromas".

"Solo estamos bromeando, así que no nos quejamos". 
"Todo es mentira porque cuando todo esto pase, seguiremos siendo la misma gentuza para ellos".

Esta narrativa muestra la distancia social entre lo que piensa la población en general sobre el origen del aplauso y la importancia que le dan los profesionales de la salud. Aun teniendo en cuenta que con el paso de las semanas hubo quejas por no seguir las restricciones de encierro, llegaron a manifestar su descontento ya que la población solo debía quedarse en casa, a diferencia del riesgo que corrían en el trabajo. Incluso consideran que el aplauso está asociado a un momento de distensión social donde los vecinos aprovechan este período para retomar, dentro de la informalidad, las relaciones sociales:

"Agradecimiento a las personas que podrían haber hecho más que aplaudir, pero que en casa están encantadas de aplaudir e infectar a los demás".

“Apoyo, pero no para todos, unidad ya que todos los vecinos salen, dejando a un lado sus diferencias y tertulias, para relacionarse".

En la segunda de las imágenes aparece el presidente del Gobierno, Pedro Sánchez, realizando una de las tradicionales apariciones de fin de semana donde se anunció la implementación de medidas para combatir el COVID-19 (Figura 2).

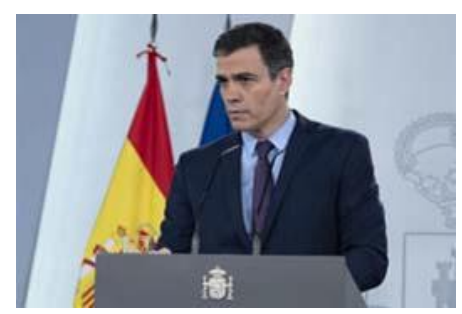

Figura 2: El presidente del Gobierno, Pedro Sánchez, haciendo una de las apariciones del fin de semana.

Fuente: La Moncloa. https://cutt.ly/Yhe1KvW

Si bien los profesionales de la salud en sus discursos responsabilizaron a los representantes políticos de la situación que vivimos, personalizan sus quejas en la figura del Presidente del Gobierno. Destacan el enfado y el desdén con el que llevan a cabo algunas de sus manifestaciones:

"Complacencia, falta de autocrítica e ignorancia".

"Decepción, engaño, desconfianza, miedo, incertidumbre, manipulación, siento que nos han tratado como si fuéramos ignorantes, esos discursos con palabras vacías que no daban instrucciones explícitas, pero que nos desconcertaron”.

"Descontrol, desconfianza, miedo, hipocresía, ladrones, asesinos". "Unas ganas de gritar y no parar...".

$\mathrm{Si}$ bien algunos mensajes positivos se identifican con su situación como responsable de la formulación de políticas, estos son muy limitados:

"Parece un hombre con miedo, con mucha responsabilidad y tratando de hacer lo mejor para todos". 
"No me gustaría verme en los zapatos de quienes han tenido y tendrán que dirigir los destinos de este barco ahora a la deriva. Sin embargo, asumo lo mejor de sus voluntades y, a pesar de los errores y lo que puedan hacer mal, creo que otros en su lugar serían igual de malos o peores".

La tercera imagen muestra a los trabajadores de la salud envueltos en bolsas de plástico como EPP (Figura 3). Uno de los trabajadores de la salud tiene el pulgar hacia abajo en señal de desaprobación.

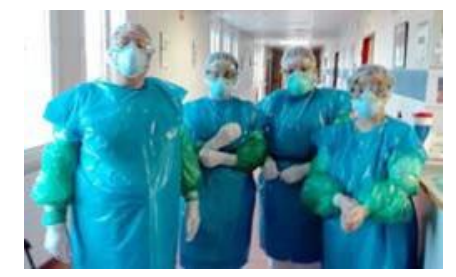

Figura 3: Profesionales de la salud del Hospital Monte San Isidro utilizan bolsas de basura para fabricar EPP.

Fuente: Leonoticias. https://cutt.ly/Yhe9f9N

Los profesionales de la salud vuelven a enfatizar la situación de desprotección en la que se encuentran, a pesar de estar en la primera línea de trabajo:

"Ira, irritación, malestar, sentirse solo o abandonado al azar. Falta de protección individual, exceso de pacientes, la presión de atender".

"Entre el personal de trabajo de los diferentes centros, ha existido una sensación de impotencia ante el contacto con personas infectadas sin el equipo de protección adecuado. Así, improvisando muchas veces con el riesgo y peligro de infectarse y contagiar".

"Un grupo de profesionales enojados, me imagino que por la falta de EPP y la necesidad de usar bolsas de basura, con miedo, con rabia, frustración y que no entienden cómo arriesgan su vida mientras algunos políticos dicen que no ha habido falta de equipos de protección en ningún servicio".

En la cuarta imagen aparece el hospital de campaña establecido en IFEMA (Madrid) (Figura 4). Esto se percibe como el punto crítico de la pandemia, de la ausencia de infraestructuras en la Comunidad de Madrid, y reconocimiento por parte de los profesionales que tuvieron que trabajar en esas condiciones.

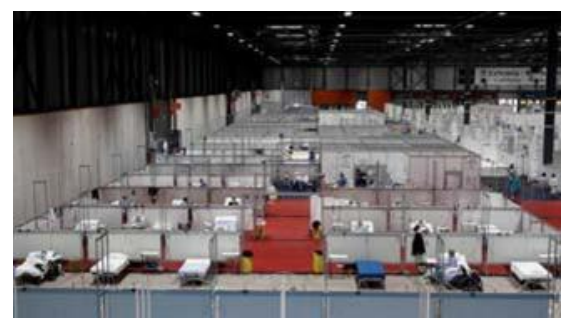

Figura 4: El hospital de campaña se estableció en IFEMA (Madrid).

Fuente: RTVE. https://cutt.ly/Ahe0d9A

Lo identifican con la mala gestión, una medida extrema ante la incapacidad de los políticos para gestionar adecuadamente esta crisis de salud: 
"Algo que ahora es necesario pero que nunca debería haber sucedido si la gestión hubiera sido eficaz".

"Colapso, reacción, lucha, superación".

"Falta de previsión, las medidas se toman tarde, falta de intimidad, hacinamiento". "Hospital de campaña, hacinamiento, poco cuidado personal".

"Manipulación hacia la opinión pública, el esfuerzo de los profesionales de IFEMA ha sido encomiable, pero no es el lugar para atender a pacientes graves en UCI, ha sido un parche por la falta de previsión y anticipación a lo que estaba por venir. Desde diciembre, podías verlo venir, y si pensabas esto, te tildaban de alarmista".

No obstante, también se valora positivamente el hecho de haber podido trabajar en estas condiciones, de haber levantado el hospital provisional en tan poco tiempo para dar respuesta a miles de pacientes afectados:

"Fuerza para todos los compañeros que están en esos hospitales y respeto para ellos".

"Hemos podido capear el temporal y montar hospitales de guerra. Se ha hecho muy bien".

"Somos héroes porque al no recibir nada lo hemos dado todo. Es nuestro, pero con los medios, no se nos ha dado".

La quinta imagen se divide en dos partes. En uno, los féretros aparecen en el Palacio de Hielo (Madrid), y en el otro, el entierro de una persona siendo enterrada por personas enmascaradas (Figura 5).

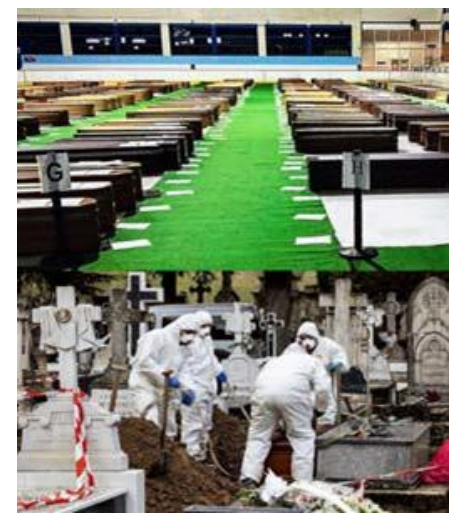

Figura 5: Palacio de Hielo (Madrid) convertido en depósito de cadáveres (superior).

Fuente: El Mundo. https://cutt.ly/nhe3UlY. Entierro en el cementerio de San José, Burgos (inferior).

Fuente: Diario de Burgos/Luis López. https://cutt.ly/phe81jP

Los informantes expresan su tristeza y desolación por estos hechos ya que en estas fotografías se visualiza la tragedia y se reconecta el proceso de luto en esos momentos difíciles:

"Desastre, dolor, tristeza, exceso de muertes, hacinamiento, confusión para identificar, sin un adiós adecuado". 
"Dolor y tristeza... por la gran cantidad de personas y familias afectadas, y, sobre todo, porque junto al dolor de la muerte, no ha sido posible despedirnos como nuestra cultura nos ha acostumbrado a hacer. Así que me imagino que tendrá un efecto muy negativo en el proceso de duelo".

"Las consecuencias de una catástrofe. Despedidas poco humanas, mucha soledad y el último adiós que creo que nadie se merece, ni como fallecido ni como familiar".

Incluso relacionan estas situaciones nuevamente con la gestión realizada. Las muertes están íntimamente ligadas a decisiones políticas y a la adopción o ausencia de medidas. Por tanto, vemos las conexiones constantes entre mortalidad y gestión pública en las narrativas de los entrevistados:

"Impotencia, por no haber puesto las medidas antes y haber evitado tantas muertes y tanto dolor".

"Consecuencias de la mala gestión". "Demasiadas muertes evitables".

"Desborde, falta de previsión política, desolación".

La última de las imágenes mostradas es quizás una de las más controvertidas, ya que muestra a mujeres en el mitin para conmemorar el 8 de marzo (Figura 6).

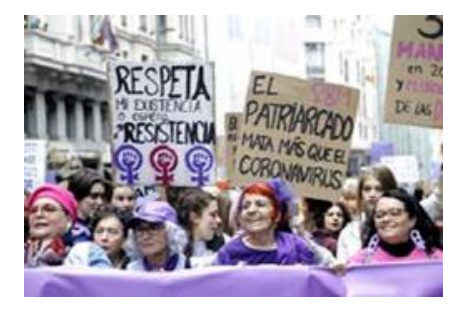

Figura 6: Manifestación del 8 de marzo (8-M) en Madrid.

Fuente: El Diario. https://cutt.ly/Bhe8GIK

Uno de ellos sostiene una pancarta con el lema: el patriarcado mata más que el coronavirus. El motivo de mostrar esta última imagen es por el carácter político y mediático que había tenido esta concentración días antes de que se declarara el estado de alarma. Los medios de comunicación y los partidos políticos han utilizado este mitin para desacreditar puntos de vista opuestos, y el gobierno ha sido acusado de retrasar las medidas al mantener este mitin con la información que tenía en ese momento sobre el coronavirus:

"Contagio masivo. Aunque esta no fue la única movilización masiva, todas las reuniones de más de 20 personas deberían haberse detenido una semana antes".

"Indignación. Eventos como este, si hubieran sido prohibidos, el resultado ahora sería menos muertes". "Ideología sobre seguridad".

"Irresponsable, imprudente, loco y responsable de la magnitud del problema actual".

Sin embargo, también mantienen una posición equidistante ya que, si bien se reconoce la necesidad de la manifestación dada la desigualdad de género en todos los espacios públicos, y la dificultad para erradicar la violencia de género, también se duda si el gobierno actuó adecuadamente al permitirla. 
"Tienen el derecho, pero si el gobierno conocía el riesgo de propagación, debería haberlo prohibido e informado el motivo con el mayor detalle posible".

"Libertad de expresión, pero los que tenían que detenerla no quisieron porque la política antecede a la vida humana".

"Una manifestación necesaria, que este año ha sido desastrosa, pero nadie previó lo que vendría".

\section{Conclusión}

Entre todas las hipótesis y discusiones que subyacen a la pandemia que arrasa todo el planeta, la representación social de la estructura que conforma la civilización en la que vivimos, donde la cultura, como parte influyente de la existencia, juega un papel determinante. La vida y la muerte adquieren representaciones en continuo cambio para adaptarse a las nuevas formas de vida que ha generado esta situación, en la que se ha visto afectada toda la sociedad.

Como parte fundamental de la recuperación física, los trabajadores de la salud han sido los actores principales, asumiendo al mismo tiempo diferentes roles: trabajadores de la salud, terapeutas, pacientes, familiares, etc., debiendo, además, realizar su labor profesional, con mucha más carga de trabajo, no ajena a la emoción que la salud-enfermedad-cuidado provoca en todo ser humano. Este hecho ha significado en ocasiones cambios en sus hábitos, como la ingesta de alimentos poco saludables, ansiolíticos, y el aumento de hábitos saludables como una buena alimentación o ejercicio físico, desde una perspectiva de prevención de enfermedades y mantenimiento de su salud.

Finalmente, los profesionales de la salud critican el manejo de la crisis por parte de los líderes políticos e institucionales, no sintiéndose representados por ellos y percibiendo que han sido puestos en "primera línea de batalla" sin los medios y protección adecuados, expuestos, por tanto, a una alta vulnerabilidad.

Por supuesto, la recuperación de todos los estratos que se han visto afectados dependerá de muchos elementos bien conectados, pero, sobre todo, requerirá un buen cambio entre los aspectos biopsicosociales y culturales en los que nos desenvolvemos los seres humanos en todo el planeta.

Esta investigación se ha desarrollado en un contexto de gran dificultad para acceder a los profesionales sanitarios debido a las circunstancias sociales y sanitarias derivadas de la primera ola. Uno de ellos es la muestra y su ubicación territorial. Aunque estos datos no pueden extrapolarse a España, esto no debe considerarse un sesgo porque se trata de un estudio pionero sobre cómo los profesionales sanitarios afrontaron el primer impacto del COVID-19. Los discursos, percepciones, disposiciones, etc., de los participantes, son de gran valor científico y merecen ser destacados, aunque no pueden generalizarse. Esta primera limitación está ligada a una segunda: la falta de distancia con el hecho estudiado. Es decir, el desconocimiento de la situación que se genera en el sistema de salud, el miedo a lo desconocido y la incertidumbre de las posibles consecuencias sociales, políticas, económicas y culturales juegan un papel fundamental en el discurso de los actores sociales.

Agradecimientos: Queremos agradecer a los trabajadores de la salud por su valioso tiempo, principalmente por las circunstancias adversas que enfrentaron, en la realización de esta investigación. 


\section{Referencias}

Aladro Vico, E. (2020). Comunicación sostenible y sociedad 2.0: particularidades en una relación de tres décadas. Revista de Comunicación de la SEECI, 53, 37-51. https://doi.org/10.15198/seeci.2020.53.37-51

Aneas, M. A., \& Sandín, M. P. (2009). Intercultural and cross-cultural communication research: Some reflections about culture and qualitative methods. Forum: Qualitative Social Research, 10(1), 1- 19.

Antón, F. (2013). Aproximación antropológica a la seguridad. Universitas, 19, 73-100. https://doi.org/10.17163/uni.n19.2013.03

Bacallao-Pino, L. M. (2016). Dimensiones de la mediación comunicativa en los movimientos sociales latinoamericanos. Perspectivas de la Comunicación, 9(1), 65-81.

Barrientos-Báez, A. (2019a). El desarrollo de la inteligencia emocional en los estudios del Grado en Turismo en la Universidad de La Laguna (Tenerife). Tesis Doctoral. Universidad Camilo José Cela. https://bit.ly/3wWEPnk

Barrientos-Báez, A. (2019b). Redes sociales, salud física e inteligencia emocional. En VV.AA. Tecnología Digital para la Salud y la Actividad Física (pp. 291-315). Pirámide.

Barrientos-Báez, A., Barquero-Cabrero, M., \& Rodríguez-Terceño, J. (2019). La educación emocional como contenido transversal para una nueva política educativa: el caso del grado de turismo. Revista Utopía y Praxis Latinoamericana, 24(4), 147-165. https://produccioncientificaluz.org/index.php/utopia/article/view/29796

Bellizzi, S., Fiamma, M., Arru, L., Farina, G., \& Manca, A. (2020). Covid-19: The daunting experience of health workers in Sardinia, Italy. Infection Control \& Hospital Epidemiology, 41(9), 1118-1119. https://doi.org/10.1017/ice.2020.149

Castañeda-Hernández, D. M., \& Rodríguez López, J. I. (2020). Covid 19 - La pandemia. Una mirada a sus impactos en Latinoamérica. Revista Venezolana de Gerencia, 25(91), 746-753. https://doi.org/10.37960/rvg.v25i91.33162

Cerezo Prieto, M. (2020). Sesgos cognitivos en la comunicación y prevención de la covid-19. Revista Latina de Comunicación Social, 78, 419-435. www.doi.org/10.4185/RLCS-2020-1483

Díaz, Z., Aguilar, T., \& Linares, X. (2015). La antropología médica aplicada a la salud pública. Revista Cubana de Salud Pública, 41(4), 655-665. https://doi.org/10.1590/s0864$\underline{34662009000100010}$

Escobar, A. (2005). Bienvenidos a Cyberia: Notas para una antropología de la cibercultura. Revista de Estudios Sociales, 22, 15-35. https://doi.org/10.7440/res22.2005.01

Fernández, G., Farina, P., Arráiz de Fernández, C., \& Troya, E. (2020). Consecuencias del maltrato infantil en un hospital de Maracaibo-Venezuela. Revista de Ciencias Sociales, 26(1), 187-202. https://doi.org/10.31876/rcs.v26i1.31319 
García-Martín, I., Ortega-Mohedano, F., \& Pérez-Peláez, M. E. (2021). Comunicación y espacios culturales en tiempos de covid-19. Vivat Academia, Revista de Comunicación, 154, 21-43. https://doi.org/10.15178/va.2021.154.e1261

García Otero, R., \& Hernández Palma, O. I. (2020). Derechos humanos y mecanismos de control normativo internacional en el marco de la pandemia covid-19: reflexión desde el control de convencionalidad. Utopía y Praxis Latinoamericana, 25(1), 116-132.

https://produccioncientificaluz.org/index.php/utopia/article/view/34164

Gómez Cardona, L. (2013). Por una antropología médica crítica hoy. Maguaré, 27(2), 21-65.

Gómez-Galán, J. (2015). Los medios de comunicación en la globalización: Implicaciones culturales, educativas y éticas. In O. Támez (Ed.), Ética, Gobernanza y Desarrollo (pp. 31-47). Málaga: SAI. Gómez-Galán, J. (2020). The black death and other historical pandemics. Frontiers of Science, 7 , $62-75$.

Gómez-Galán, J. (2020). Media education in the ICT era: Theoretical structure for innovative teaching styles. Information, 11(5), 276. https://doi.org/10.3390/info11050276

Guanche, H. (2020). Covid-19. A challenge for healthcare professionals. Revista Habanera de Ciencias Médicas, 19(2), 1-3.

Guerra Rubio, L. M., \& Eiriz García, O. (2018). El dengue: su enfoque comunicativo, aciertos y desafíos. Revista de Comunicación y Salud, 8(2), 51-64.

http://doi.org/10.35669/revistadecomunicacionysalud.2018.8(2).51-64

Hartley, J., Ibrus, I., \& Ojamaa, M. (2020). On the Digital Semiosphere: Culture, Media and Science for the Anthropocene. New York: Bloomsbury Publishing USA.

Hernández-Fernández, L. (2021). Editorial 2020, un año de dificultades y retos tras el covid-19. Revista de Ciencias $\quad$ Sociales, $\quad 27(1), \quad 7-10$. https://produccioncientificaluz.org/index.php/rcs/article/view/35324

Herrero, J. C., \& Toledo Chávarri, A. (2012). La profesionalización de la comunicación para el desarrollo: relaciones entre la teoría y la práctica. CIC. Cuadernos de Información y Comunicación, 17, 255-266. https://doi.org/10.5209/rev_CIYC 2012.v17.39267

Hsieh, E., \& Kramer, E. M. (2021). Rethinking Culture in Health Communication: Social Interactions as Intercultural Encounters. John Wiley \& Sons.

Huremović, D. (2019). Psychiatry of pandemics. Springer Nature.

Junge P. (2001). Nuevos paradigmas en la antropología médica. In Actas del IV Congreso Chileno de Antropología (pp. 18-23). Santiago de Chile: Colegio de Antropólogos de Chile.

Kristensen, N. N. (2021). Rethinking Cultural Criticism: New Voices in the Digital Age. Springer Nature. 
Lázaro-Pérez, C., Jimenez, F., \& Correa, M. (2017). La muerte del ser humano. In F. Jimenez, P. Román, \& M. Díaz (Eds). Cuidados de Enfermería en Situaciones Complejas de Salud: Proceso Oncológico, Cuidados Paliativos, Muerte y Duelo (pp. 34-41). Univesidad de Almería.

Lévi-Strauss, C. (1994). Saudade do Brasil. Plon.

Lominchar Jiménez, J. (2020). Visión del cambio Covid-19: Impacto en la fuerza de trabajo y profesionales autónomos. Revista Venezolana de Gerencia, 25(4), 12-31. https://produccioncientificaluz.org/index.php/rvg/article/view/35213

Lora Ochoa, C., Anaya Narváez, A., \& Pinedo López, J. (2020). Economía social y Covid-19: aportes y perspectivas en Colombia. Utopía y Praxis Latinoamericana, 25(1), 303-320. https://produccioncientificaluz.org/index.php/utopia/article/view/34185

Malinowski, B. (1967). A Diary in the Strict Sense of the Term. Harcourt, Brace \& World. MartínAntoranz, P., Cabezuelo-Lorenzo, F., \& Bartolomé-Muñoz-de-Luna, Ángel. (2019). Competencias y formación ética de los profesionales de la comunicación corporativa en contextos interculturales. Revista de Ciencias de la Comunicación e Información, 24(1), 59-72. https://doi.org/10.35742/rcci.2019.24(1).59-72

Martínez-López, J. Á., Lázaro-Pérez, C., Gómez-Galán, J., \& Fernández-Martínez, M. D. M. (2020). Psychological impact of covid-19 emergency on health professionals: Burnout incidence at the most critical period in Spain. Journal of Clinical Medicine, 9(9), 3029. https://doi.org/10.3390/jem9093029

Martínez-López, J. Á., Lázaro-Pérez, C., \& Gómez-Galán, J. (2021). Burnout among direct-care workers in nursing homes during the covid-19 pandemic in Spain: A preventive and educational focus for sustainable workplaces. Sustainability, 13(5), 2782. https://doi.org/10.3390/su13052782

Mas Esquedo, J (2020). Secuelas psicológicas de la crisis del coronavirus en el personal sanitario e interviniente. BIE3: Boletín IEEE, 19, 607-614.

Mead, M., \& Bateson, G. (1977). On the use of the camera in anthropology. Studies in the Anthropology of Visual Communication, 4(2), 78-80. https://doi.org/10.1525/var.1977.4.2.78

Merrill, S., Keightley, E., \& Daphi, P. (Eds.). (2020). Social Movements, Cultural Memory and Digital Media: Mobilising Mediated Remembrance. Springer Nature.

Mestre Ortega, P., Bote Ruiz-de Gordoa, J. J., Mira Roldán, A., Buendía Domínguez, R., \& Bravo Hernández, M. A. (2018). Análisis de impactos de los medios de comunicación de los casos de la fiebre hemorrágica de Crimea-Congo en la Comunidad de Madrid. Revista de Comunicación y Salud, 8(1), 99-109. https://doi.org/10.35669/revistadecomunicacionysalud.2018.8(1).99-109

Molina, J. (2011). El sufrimiento humano como experiencia personal y profesional. Revista Bioética, 6, 4-9.

Páez, R. (2011). La investigación de la industria farmacéutica condicionada por los intereses del mercado. Acta Bioethica, 11(2), 237-246. https://doi.org/10.4067/s1726-569x2011000200010 Rodríguez Vidales, Y. (2010). El ala oeste de la Casa Blanca (The West Wing): Un tratado de 
Comunicación Política Institucional. CIC. Cuadernos de Información y Comunicación, 15, 85121. https://revistas.ucm.es/index.php/CIYC/article/view/CIYC1010110085A

Roman, G., Álvarez-Rementería, M., Pérez-Izaguirre, E., \& Dosil, M. (2020). El rol de los medios de comunicación en situaciones de crisis sanitaria. La percepción de la población en torno al control y las normas sociales durante la pandemia del Covid-19. Revista Latina de Comunicación Social, 78,437-456. www.doi.org/10.4185/RLCS-2020-1484

Romeu V. (2016). La posibilidad del diálogo en las relaciones interculturales. Perspectivas de la Comunicación, 9(2). 71-91.

Ruiz Torres, P. (2021). Covid-19: Teletrabajo en tiempos de pandemia. Historia y Comunicación Social, 26(Especial), 11-18. https://doi.org/10.5209/hics.74237

Russell, H. (1995). Métodos de Investigación en Antropología. Altamira Press.

Saborío, L., \& Hidalgo, L.F. (2015). Síndrome de Burnout. Medicina Legal de Costa Rica, 32(1), 119- 124.

Sanjuán-Pérez, A., Martínez-Costa, S., Videla-Rodríguez, J. J., \& Nozal-Cantarero, T. (2020). Información sobre coronavirus y covid-19 en las principales cadenas españolas de TV en el período previo al confinamiento. Profesional de la Información, 29(6), e290611. https://doi.org/10.3145/epi.2020.nov.11

Santamarina, B. (2008). Antropología y medio ambiente. Revisión de una tradición y nuevas perspectivas de análisis en la problemática ecológica. AIBR, 3(2), 144-184. https://doi.org/10.11156/aibr.030203

Semple, S., \& Cherrie, J. W. (2020). Covid-19: Protecting worker health. Annals of Work Exposures and Health, 64(5), 461-464. https://doi.org/10.1093/annweh/wxaa033

Sarmiento Guede, J. R., \& Rodríguez Terceño, J. (2018). La comunicación de boca en boca electrónica en los medios sociales. Análisis de sus antecedentes. Revista de Comunicación de la SEECI, 45, 129-148. http://doi.org/10.15198/seeci.2018.45.129-148

Sevilla, M., \& Álvarez, N. (2002). La enfermedad del SIDA: Un estudio antropológico desde la perspectiva del discurso. Cuicuilcuo, 9(24), 191-216.

Sheldon, P., Herzfeldt, E., \& Rauschnabel, P. A. (2020). Culture and social media: The relationship between cultural values and hashtagging styles. Behaviour \& Information Technology, 39(7), 758770. https://doi.org/10.1080/0144929x.2019.1611923

Tomasello, M. (2010). Origins of Human Communication. MIT Press.

Van Ommeren, M., \& Saxena S. (2005). Aid after disasters. BMJ, 330, 1160-1161. https://doi.org/10.1136/sbmj.0506223

Vargas, L. A., \& Casillas. L. E. (2007). Perspectiva antropológica de la consulta médica: Entre la ciencia y el arte de la medicina. In C. Tena, \& F. Hernández-Orozco (Eds.). La Comunicación Humana en la Relación Médico-Paciente (pp. 79-110). Editorial Prado and CONAMED. 
Vargas Delgado, J. J. (2020). Stress coaching 0.0. Experimental programa de coaching para reducir el estrés. Revista de Ciencias de la Comunicación e Información, 25(2), 71-90. https://doi.org/10.35742/rcci.2020.25(2).71-90

Vázquez, A. (2008). Peter Sloterdijk: Espacio tanatológico, duelo esférico y disposición melancólica. Nómadas. Revista Crítica de Ciencias Sociales y Jurídicas, 17, 159-170.

Vega Jiménez, P. (2021). Costa Rica: dos pandemias en un siglo. Historia y Comunicación Social, 26(Especial), 1-10. https://doi.org/10.5209/hics.74236

\section{AUTORES:}

\section{Cristina Lázaro Pérez}

Profesora de la Universidad de Murcia (España). Doctora en Antropología por la Universidad de Murcia, Licenciada en Psicología y Master en Psicooncología, Antropología, etc. Pertenece a los grupos de investigación "Conciencia, Cultura e Identidad" y "Sociología del Bienestar Social y el Envejecimiento" de la Universidad de Murcia y al Instituto Universitario de Investigación en Envejecimiento. Autora de libros y múltiples artículos científicos, de los que se pueden destacar los recogidos en los cuartiles Q1 y Q2 de JCR y Scopus. Ha asistido como ponente a numerosos congresos educativos y científicos en diferentes países. Sus principales investigaciones han sido desarrolladas en contexto hospitalario.

cristina.lazaro2@um.es

\section{Índice H: 7}

Orcid ID: https://orcid.org/0000-0002-1316-0201

Research Gate: https://www.researchgate.net/profile/Cristina-Lazaro-Perez

\section{José Ángel Martínez López}

Profesor Contratado Doctor (acreditado a Profesor Titular) y Vicedecano de Prácticas y Empleabilidad en la Facultad de Trabajo de la Universidad de Murcia (España). Es Máster en Problemas Sociales (UNED) y Doctor en Sociología (Universidad de Murcia). Ha sido profesor visitante en la Universidad Complutense de Madrid (España) y la Conventry University (Reino Unido). Autor de decenas de publicaciones científicas, de las que se pueden destacar las recogidas en los cuartiles Q1 y Q2 de JCR y Scopus. Fruto de su trayectoria científica y académica ha presentado más de veinte comunicaciones en congresos de investigación y docentes, tanto nacionales como internacionales. Coordinador de la Oficina de Atención Social en la Universidad de Murcia. jaml@um.es

\section{Índice H: 8}

Orcid ID: https://orcid.org/0000-0002-6871-7265

Research Gate: https://www.researchgate.net/profile/Jose-Angel-Martinez-Lopez

\section{José Gómez Galán}

Catedrático de la Universidad de Extremadura (España) y Research Professor en la Universidad Ana G. Méndez (Puerto Rico-Estados Unidos). Doctor en Filosofía y CC. de la Educación (UNED) y Doctor en Geografía e Historia (Universidad Complutense de Madrid). Premio Nacional de Investigación Educativa y Premio a la Excelencia Docente (DOCENTIA). Director de grupos de investigación a escala internacional. Director de revistas académicas. Autor de más de 300 publicaciones científicas multidisciplinarias, de las que se pueden destacar las recogidas en los cuartiles Q1 y Q2 de JCR y Scopus. Ha sido profesor y/o investigador en las universidades de 
Minnesota (Estados Unidos), Oxford (Reino Unido), La Sapienza de Roma (Italia), diversas universidades iberoamericanas, etc.

jgomez@unex.es / jogomez@uagm.edu

\section{Índice H: 23}

Orcid ID: https://orcid.org/0000-0002-9417-8824

Research Gate: https://www.researchgate.net/profile/Jose-Gomez-Galan

\section{María José del Pino Espejo}

Profesora Contratada Doctora en la Universidad Pablo de Olavide (Sevilla, España). Licenciada en CC Políticas y Sociología y Doctora por la Universidad de Córdoba. Ha sido Becaria Erasmus de Posgrado en el Master en European Social Policy Analysis (Universidad de Bath, Reino Unido). Ha realizado estancias en las universidades de Tilburg (Holanda) y Maynooth (Irlanda). Becaria de posgrado Graduiertenkoleg en el MZES, Mannheim (Alemania), con estancia en el Instituto de Estudios Sociales Avanzados IESA-CSIC en Córdoba (España). Ha liderado proyectos para diversas entidades europeas. Sus principales investigaciones, la mayoría publicadas en artículos de alto impacto y presentadas en congresos, se centran en estrés, salud, violencia de género y desarrollo humano.

mjpinesp@upo.es

Índice H: 5

Orcid ID: https://orcid.org/0000-0002-5271-5820

Research Gate: https://www.researchgate.net/profile/Maria-Espejo-3 